\title{
Efeito da Restrição Alimentar no Desempenho Produtivo e Econômico de Cabritos F1 Boer x Saanen
}

\author{
José Morais Pereira Filho', Kleber Tomás de Resende ${ }^{2}$, Izabelle Auxiliadora Molina de Almeida \\ Teixeira $^{3}$, Américo Garcia da Silva Sobrinho², Enrique Alejandro Yáñez ${ }^{4}$, Angela Cristina Dias Ferreira ${ }^{3}$
}

RESUMO - Objetivou-se, com este trabalho, avaliar o efeito dos níveis de restrição alimentar (0,30 e 60\%) sobre o desempenho produtivo e econômico de cabritos F1 Boer x Saanen. Foram utilizados 21 cabritos inteiro, com média de 15,44 $\pm 0,37$ kg de peso vivo (PV). Os animais do nível de restrição 0\%, quando atingiram $25 \mathrm{~kg}$ de PV, foram submetidos a jejum (sólido de 24 horas e hídrico de 16 horas) e abatidos com seus pares. A análise econômica foi referente, exclusivamente, aos custos com alimentação (U \$1,00:R $\$ 3,70)$. A eficiência alimentar dos animais submetidos a 0 e $30 \%$ de restrição não diferiu. A restrição teve efeito linear decrescente para renda bruta média, quadrática para margem bruta média e rentabilidade média. Houve redução do custo da alimentação por kg de corpo vazio, de carcaça quente e de carcaça fria. A restrição em níveis moderados manteve a eficiência alimentar e reduziu as perdas com alimentação. A criação de cabrito leiteiro para abate entre 20 e $25 \mathrm{~kg}$ de PV, com restrição a partir dos $15 \mathrm{~kg}$, aumentou a rentabilidade sobre o investimento em alimentação até o nível de 15,59\% e diminuiu os custos com alimentação por kg de carcaça fria até o nível de 16,13\% de restrição, caracterizando-se como alternativa ao sacrifício desses animais e à agregação de valor ao sistema de produção. Por outro lado, a compra de cabritos a preço de mercado para terminação até $25 \mathrm{~kg}$ de PV caracterizou-se como atividade de risco.

Palavras-chave: eficiência alimentar, peso de carcaça fria, rentabilidade média

\section{Effect of Feed Restriction on Economical and Productive Performances of F1-Boer $\mathbf{x}$ Saanen Goats}

\begin{abstract}
The goal of this study was to evaluate the effect of different feed restriction levels (0,30 and $60 \%)$ on economical and productive performances of F1-Boer $x$ Saanen goats. Twenty-one non-castrated goats with $15.44 \pm 0.37 \mathrm{~kg}$ of mean live weight (LW) were used. When animals submitted to $0 \%$ of feed restriction reached $25 \mathrm{~kg}$ of $\mathrm{LW}$ they and their pair were slaughtered after $24 \mathrm{~h}$ of feed fasting and $16 \mathrm{~h}$ of water fasting. Economical analysis was performed considering exclusively feed costs and the currency conversion $(\mathrm{U} \$ 1.00=\mathrm{R} \$ 3.70)$ at the period in which trial was carried out. There was no difference between feed conversions of animals submitted to 0 and $30 \%$ of restriction. Restriction had decreasing linear effect on average gross revenue, quadratic effect on average gross margin and average profitability. It was observed reduction in feed cost per $\mathrm{kg}$ of empty body, hot carcass and cold carcass. Restriction in moderate levels maintained feed conversion efficiency and reduced feed losses. Dairy goat breeding for slaughtering between 20 to $25 \mathrm{~kg}$ of LW with feed restriction from $15 \mathrm{~kg}$ increased profitability on feed investments until the level of $15.59 \%$; and decreased feed costs per kg of cold carcass until the level of $16.13 \%$ of restriction. This strategy might be considered as an alternative for avoiding these animal sacrifices and for aggregation of value to production system. The goat buy at marked prices for finishing until $25 \mathrm{~kg}$ of LW seems to be a high-risk activity.
\end{abstract}

Key Words: feed efficiency, cold carcass weight, mean profitability

\section{Introdução}

$\mathrm{Na}$ caprinocultura leiteira, os produtores optam pelo sacrifício dos cabritos logo após o nascimento, para minimizar custos, concentrando esforços na produção de leite. Por outro lado, a espécie caprina, quando bem manejada, pode manter índice de um parto a cada oito meses e prolificidade de 1,5 a 1,8 cria por parto (Resende, 2002), significando o sacrifício de muitos animais.

Diante desse quadro, alguns produtores de leite admitem a possibilidade de criação dos machos e do excedente de fêmeas para obtenção de animais com peso médio de $25 \mathrm{~kg}$ para comercialização de carcaças

\footnotetext{
1 Professor do Departamento de Medicina Veterinária da Universidade Federal da Paraíba - UFPB, Caixa Postal 64, Cep: 58708-110, Patos-PB (jmorais@cstr.ufcg.edu.br; jmpfpiaui@ig.com.br)

2 Professor do Departamento de Zootecnia da FCAV/Unesp, Jaboticabal-SP (kresende@fcav.unesp.br). Bolsista do CNPq.

3 Bolsista da FAPESP e Pós-Graduando em Zootecnia, FCAV/Unesp, Jaboticabal-SP.

${ }^{4}$ Professor do Departamento de Producción Animal da Facultad de Ciencias Veterinarias, UNNE, Corrientes. Sargento Cabral 2139 Corrientes, Argentina. CP: 3400 (eyanez@vet.unne.edu.ar).
} 
leves (10 a $12 \mathrm{~kg}$ ). Nos últimos anos, alguns caprinocultores da região Sudeste têm introduzido reprodutores da raça Boer para cobrir parte das fêmeas leiteiras, com o objetivo de incrementar o ganho de peso e melhorar as características de carcaça. No Brasil, existem poucas pesquisas sobre a espécie caprina que avaliam o crescimento animal e a qualidade da carcaça, sendo rara a associação desses aspectos com a resposta econômica, principalmente quando se trata da raça Boer, que, segundo Oman et al. (1999) se caracteriza como melhoradora em cruzamentos com caprinos nativos e se destaca pela conformação para produção de carne.

A busca de alternativas para reduzir custos de produção e garantir maior competitividade é um ponto importante na sustentabilidade de qualquer atividade econômica. Na caprinocultura leiteira, as despesas com alimentação representam de 50 a $60 \%$ dos custos de produção e, dependendo do contexto, atingem até 80\% (Ribeiro, 1997). Na criação de ruminantes, especialmente de caprinos, o caminho natural para a redução de custos é a exploração da capacidade desses animais de digerir alimentos fibrosos (MoronFuenmayor \& Clavero, 1999). Recorre-se também a alternativas como: restrição qualitativa com diferentes teores de proteína, (Mtenga \& Kitaly, 1990); restrição alimentar e exploração do crescimento compensatório (Sahlu et al., 1999); e utilização de dieta única com restrição quantitativa (Yáñez, 2002).

Mejía et al. (1996a), trabalhando com bezerros na fase de aleitamento, verificaram que as despesas com alimentação representaram $67,60 \%$ dos custos operacionais totais, dos quais o leite foi responsável por $91,60 \%$, o concentrado por $8,04 \%$ e o volumoso por $0,37 \%$. Para a fase de pós-aleitamento, Mejía et al. (1996b) destacaram a importância do custo relativo do concentrado, posto que o custo de alimento por $\mathrm{kg}$ de ganho de PV decresce à medida que se aumenta o nível de concentrado.

A restrição alimentar é uma prática comum na criação de bovinos jovens, com o objetivo de explorar o crescimento compensatório. Arrigoni et al. (1998), trabalhando com bovinos inteiros, oriundos do cruzamento Simental x Nelore, concluíram que a restrição alimentar permitiu explorar o ganho compensatório, resultando em melhor conversão alimentar, graças à diminuição das exigências de manutenção.

É importante considerar que, à medida que a maturidade fisiológica do animal se aproxima, diminui a taxa de deposição de massa muscular e aumenta a de gordura, que, no caprino, se caracteriza, principalmente, pelo acúmulo de gordura visceral, produto de pouco valor comercial.

Na restrição alimentar quantitativa, é desejável que a quantidade oferecida para atingir o melhor ajuste da quantidade ingerida proporcione o melhor ganho de peso e reduza os custos com alimentação por kg de carcaça fria. Portanto, objetivou-se, com este trabalho, avaliar o efeito da restrição alimentar sobre o desempenho produtivo e econômico de cabritos F1 Boer x Saanen.

\section{Material e Métodos}

O trabalho foi realizado no Setor de Caprinos da FCAV/Unesp, em Jaboticabal, São Paulo. Vinte e um cabritos inteiros (F1 Boer x Saanen) com peso médio de 15,44 \pm 0,37 $\mathrm{kg}$ de PV foram distribuídos nos tratamentos e alojados em gaiolas individuais.

O manejo alimentar durante o aleitamento consistiu no fornecimento de colostro de vaca durante dois dias, seguido do fornecimento de 1,5 litro/dia de leite de vaca, dividido em duas refeições, e desaleitamento no $50^{\circ}$ dia. A dieta sólida foi formulada com base nas exigências em proteína e energia metabolizável para ganho de $150 \mathrm{~g} /$ dia (AFRC, 1998), fornecida à vontade, a partir do 7 o dia, até os cabritos atingirem $15 \mathrm{~kg}$ de PV, quando foram distribuídos nos tratamentos.

Os ingredientes utilizados na dieta (feno da planta de milho, 46,88\%; milho moído, 25,91\%; farelo de soja, 19,32\%; melaço de cana-de-açúcar, 4,29\%; óleo de soja, $0,81 \%$; núcleo mineral, $1,99 \%$; e calcário calcítico, $0,80 \%$ ) foram processados e fornecidos na forma de ração completa. A composição químico-bromatológica da dieta é apresentada na Tabela 1. Os tratamentos utilizados foram: $0 \%$ de restrição (alimentação à vontade), $30 \%$ e $60 \%$ de restrição em relação ao consumido pelos animais alimentados à vontade.

O acompanhamento do desenvolvimento dos animais foi feito por pesagens semanais até que os animais do nível de restrição $0 \%$ atingissem $25 \mathrm{~kg}$ de PV, quando, juntamente com seus pares, foram submetidos a jejum alimentar (24 horas) e hídrico (16 horas). Os animais foram pesados antes e após o jejum, obtendo-se o peso vivo (PV) e o peso em jejum (PJ).

$\mathrm{O}$ abate foi feito mediante descarga elétrica, seguido de sangria, esfola e retirada dos órgãos. O trato gastrintestinal foi esvaziado e limpo para obtenção do peso do corpo vazio (PCV), que foi calculado subtraindo o conteúdo gastrintestinal e o líquido con-

R. Bras. Zootec., v.34, n.1, p.188-196, 2005 
Tabela 1 - Composição química da dieta

Table 1 - Chemical composition of the diet

\begin{tabular}{|c|c|}
\hline $\begin{array}{l}\text { Componente } \\
\text { Component }\end{array}$ & $\%$ \\
\hline Matéria seca & 89,32 \\
\hline Dry matter & \\
\hline Proteína bruta ${ }^{1}$ & 16,50 \\
\hline $\begin{array}{l}\text { Crude protein } \\
\text { Extrato etéreo }^{1}\end{array}$ & 3,56 \\
\hline Ether extract & \\
\hline $\begin{array}{l}\text { Energia metabolizável (Mcal/kg MS) } \\
\text { Metabolizable energy }\end{array}$ & 2,46 \\
\hline $\begin{array}{l}\text { Fibra em detergente neutro }{ }^{1} \\
\text { Neutral detergent fiber }\end{array}$ & 48,82 \\
\hline $\begin{array}{l}\text { Fibra em detergente ácido }{ }^{1} \\
\text { Acid detergent fiber }\end{array}$ & 17,72 \\
\hline $\begin{array}{l}\text { Cálcio } 1 \\
\text { Calcium }\end{array}$ & 0,65 \\
\hline $\begin{array}{l}\text { Fósforo }{ }^{1} \\
\text { Phosphorus }\end{array}$ & 0,32 \\
\hline
\end{tabular}

${ }^{1}$ Valores expressos com base na matéria seca.

1 Values expressed based on dry matter.

tido na bexiga e na vesícula biliar do PJ. A carcaça foi obtida após a separação das mãos e dos pés na articulação carpo metacarpiana e tarso metatarsiana, respectivamente, e a cabeça na articulação atlantooccipital, e pesadas para obtenção de peso da carcaça quente (PCQ). As carcaças foram mantidas em câmara fria por 24 horas, a $5^{\circ} \mathrm{C}$, e pesadas, obtendo-se o peso da carcaça fria (PCF).

Como na maioria dos sistemas de produção os machos recém-nascidos são sacrificados, o impacto econômico da restrição alimentar foi analisado sob duas condições: na primeira, foi atribuído custo zero para obtenção dos cabritos, e a análise econômica foi feita com base no sorteio de todos os animais com 15 $\mathrm{kg}$ e custo de 2,25 reais por kg de PV, que corresponde aos custos com alimentação do nascimento aos $15 \mathrm{~kg}$; na segunda, foi considerado o custo de oportunidade, ou seja, o custo inicial do cabrito não foi estimado pelo custo da alimentação até os $15 \mathrm{~kg}$ de PV, e sim pelo preço de mercado do $\mathrm{kg}$ de $\mathrm{PV}$, que neste caso passaria de $\mathrm{R} \$ 2,25$ para $\mathrm{R} \$ 3,50$.

É importante mencionar que a análise econômica consistiu da produção do cabrito e do custo com alimentação. Os custos com instalações e mão-de-obra variam em função das características de cada sistema de produção e seriam "fixos" para sistemas semelhantes que adotassem as mesmas condições de manejo.
Para o cálculo do custo da ração completa, os ingredientes foram cotados em outubro de 2002, considerando o preço médio adotado na região de Jaboticabal e os preços cotados pela Escola Superior Luis de Queiroz (CEPEA, 2002), quando o câmbio era de U\$1,00:R \$3,70. Para o feno da planta de milho, foi considerado o preço da matéria seca da silagem, acrescido de $10 \%$ para corrigir os gastos com secagem e moagem do feno. Foram acrescentados ainda $2 \%$ sobre o valor total dos ingredientes para cobrir os custos com a moagem do milho e o processamento da ração completa. Assim, o custo final da ração foi de $\mathrm{R} \$ 0,42 / \mathrm{kg}$.

As variáveis utilizadas para a análise econômica foram as recomendadas por Lana et al. (1999), descritas da seguinte forma:

Receita bruta média (RBM): obtida multiplicando o peso do cabrito (PCab) pelo preço do kg de PV (PçkgPV), definida por: RBM = PCab x PçkgPV;

Custos comalimentação(CuA): obtido multiplicando o total de ração consumida (RC) pelo seu respectivo preço (PçR), definido por: $\mathrm{CuA}=\mathrm{RC}$ x PçR;

Margem bruta média (MBM): obtida pela diferença entre a receita bruta e os gastos com alimentação, definida como: $\mathrm{MBM}=\mathrm{RBM}-\mathrm{CuA}$;

Margem bruta relativa (MBR): obtida a partir do quociente entre a margem bruta média dos tratamentos com restrição e a margem bruta média do tratamento com $0 \%$ de restrição, atribuindo-se valor 100 para o tratamento $0 \%$ de restrição, conforme a fórmula:

$$
\mathrm{MBR}=\frac{\text { MBM do tratamento com restrição }}{\text { MBM do tratamento } 0 \% \text { de restrição }} \times 100
$$

A rentabilidade média (RM), expressa em porcentagem e corresponde à rentabilidade sobre o investimento em alimentação, obtida pelo quociente entre a margem bruta média e o custo com alimentação, definida por:

$$
\mathrm{RM}=\frac{\mathrm{MBM}}{\mathrm{CuA}} \times 100
$$

Índice relativo de rentabilidade (IRR): obtido pelo quociente entre a rentabilidade média dos diferentes tratamentos com restrição e a rentabilidade média do tratamento $0 \%$ de restrição, atribuindo-se o valor 100 ao IRR do tratamento $0 \%$ de restrição, definido por:

$$
\mathrm{IRR}=\frac{\mathrm{RM} \text { do tratamento com restrição }}{\mathrm{RM} \text { do tratamento } 0 \% \text { de restrição }} \times 100
$$


O delineamento experimental utilizado foi o inteiramente casualizado, com três tratamentos e sete repetições. As análises estatísticas foram feitas por intermédio de análises de variância e de regressão, segundo os procedimentos Proc Glm e Proc Reg do SAS (1999). Quando necessário, as médias foram comparadas pelo teste Tukey, a $5 \%$ de probabilidade.

\section{Resultados e Discussão}

A idade de abate dos animais variou de 112 a 114 dias. Peso final, ganho de peso total, ganho de peso médio diário, ingestão e eficiência alimentar foram influenciados pela restrição alimentar (Tabela 2).

Os bons resultados de ganho de peso e de eficiência alimentar têm relação direta com as condições experimentais, visto que os animais foram alimentados com controle individual e sob boas condições sanitárias, o que os diferencia dos cabritos sob qualquer situação de cria, recria ou engorda praticadas comercialmente. Todavia, os resultados sugerem que o destino dos cabritos em sistemas de produção de leite deve ser melhor investigado e que os machos recém-nascidos e o excedente de fêmeas podem gerar renda e agregar valor à produção de leite.

Em trabalho conduzido com cabritos Saanen em duas fases (de 5 a $20 \mathrm{~kg}$ e de 20 a $35 \mathrm{~kg}$ de PV), em condições e metodologia semelhantes às descritas neste experimento, Yáñez (2002) obteve, na primeira fase, ganhos de 213,3; 148,4 e 79,9 g/dia, respectivamente, para os níveis de 0,30 e $60 \%$ de restrição, enquanto os resultados para os mesmos tratamentos e referentes aos animais de 20 a $35 \mathrm{~kg}$ de PV foram de 217,$8 ; 120,2$ e 27,6 g/dia. Constata-se que os resultados do tratamento $0 \%$ de restrição nas duas fases foram semelhantes aos 211,0 g/dia obtidos neste trabalho.

Genandoy et al. (2002) avaliaram o desempenho de cabritos da raça Alpina submetidos a dois tratamentos (leite exclusivo à vontade e fornecimento de $1,0 \mathrm{~kg}$ de leite mais concentrado ao longo de 10 semanas de vida) e obtiveram ganho de 151 e $149 \mathrm{~g} /$ dia, respectivamente, mas, ao final da $13^{\mathrm{a}}$ semana, o ganho dos animais com restrição parcial de leite foi de $144 \mathrm{~g}$ vs $110 \mathrm{~g}$ dos alimentados somente com leite, refletindo, segundo Church (1993), a importância dos alimentos sólidos no desenvolvimento dos pré-estômagos dos ruminantes, influenciando o desempenho (Genandoy et al., 2002) e as características de carcaça (Pereira Filho et al., 2001).

Quando os alimentos que compõem a dieta dos caprinos são processados e fornecidos na forma de ração completa, as seletividades físico-químicas são reduzidas. Ainda assim, se o fornecimento for à vontade, os animais podem ingerir nutrientes em quantidades e qualidades diferentes das que foram oferecidas, aumentando as sobras, que, se não aproveitadas, diminuem a margem de lucro e podem inclusive inviabilizar a criação de cabritos.

Como os animais foram desaleitados no 50 o dia e alimentados à vontade até atingirem $15 \mathrm{~kg}$ de PV, todas as variáveis analisadas refletem o efeito da restrição de alimentos sólidos, em que a imposição dos tratamentos foi confirmada pelo consumo dos

Tabela 2 - Médias e coeficientes de variação (CV) do peso inicial, peso final, do ganho de peso total, ganho de peso diário e da eficiência alimentar (EA), de cabritos F1 Boer x Saanen, submetidos a três níveis de restrição

Table 2 - Means and coefficients of variation (CV), initial live weight (ILW), final live weight (FLW), weight gain (WG), growth rate daily (GR) and feed efficiency (FE) of Boer $x$ Saanen kids submitted to three levels of feed restriction

\begin{tabular}{lcccc}
\hline Item & \multicolumn{3}{c}{ Restrição (Restriction) } & CV (\%) \\
\cline { 2 - 4 } & \multicolumn{1}{c}{$0 \%$} & $30 \%$ & $60 \%$ & 4,03 \\
\hline $\begin{array}{l}\text { Peso inicial }(\mathrm{kg}) \\
\text { Initial weigth }\end{array}$ & 15,87 & 15,21 & 15,25 & 4,72 \\
$\begin{array}{l}\text { Peso final (kg) } \\
\text { Final weigth }\end{array}$ & $25,44 \mathrm{c}$ & $20,91 \mathrm{~b}$ & $15,82 \mathrm{a}$ & 17,94 \\
Ganho de peso total (kg) & $9,57 \mathrm{c}$ & $5,70 \mathrm{~b}$ & $0,57 \mathrm{a}$ & 18,69 \\
$\begin{array}{l}\text { Gain of total weigth } \\
\text { Ganho de peso diário (g) }\end{array}$ & $211,03 \mathrm{c}$ & $126,15 \mathrm{~b}$ & $11,71 \mathrm{a}$ & 10,59 \\
$\begin{array}{l}\text { Gain of daily weigth } \\
\text { Ingestão (\% PV) }\end{array}$ & $4,47 \mathrm{c}$ & $3,66 \mathrm{~b}$ & $2,87 \mathrm{a}$ & 29,56 \\
$\begin{array}{l}\text { Ingestion } \\
\text { EA }(F E)\end{array}$ & $0,20 \mathrm{~b}$ & $0,18 \mathrm{~b}$ & $0,03 \mathrm{a}$ &
\end{tabular}

Médias com letras diferentes, na mesma linha, diferem $(p<0,05)$ pelo teste Tukey.

Means with different letters, in the same line, differ $(p<.05)$ by Tukey test.

R. Bras. Zootec., v.34, n.1, p.188-196, 2005 
Tabela 3 - Médias e coeficientes de variação (CV) das quantidades da dieta oferecida, da ingerida e das sobras, de cabritos F1 Boer x Saanen, submetidos a três níveis de restrição

Table 3 - Average and coefficients of variation (CV) of the offered and ingested diet, and diet refusal of Boer $x$ Saanen kids submitted to three levels of feed restriction

\begin{tabular}{lccrc}
\hline Dieta (Diet) & \multicolumn{3}{c}{ Restrição(Restriction) } & CV ( \%) \\
\cline { 2 - 4 } & $0 \%$ & $30 \%$ & $60 \%$ & $19,52 \mathrm{a}$ \\
Oferecida Offered $(\mathrm{kg})$ & $54,82 \mathrm{c}$ & $33,15 \mathrm{~b}$ & $0,07 \mathrm{a}$ & 22,30 \\
Sobras orts $(\mathrm{kg})$ & $7,15 \mathrm{~b}$ & $0,40 \mathrm{a}$ & $19,45 \mathrm{a}$ & 10,55 \\
Ingerida Intake $(\mathrm{kg})$ & $47,67 \mathrm{c}$ & $32,74 \mathrm{~b}$ & \\
\hline
\end{tabular}

Médias com letras diferentes, na mesma linha, diferem $(p<0,05)$ pelo teste Tukey.

Means in the same row with different letters are significantly different $(P<.05)$ by Tukey test.

Tabela 4 - Médias, equações e coeficientes de determinação $\left(R^{2}\right)$ dos custos da dieta oferecida, da ingerida e das sobras, de cabritos F1 Boer x Saanen, em função do nível de restrição

Table 4 - Averages, equations and coefficients of determination $\left(R^{2}\right)$ of the costs of the offered diet, of the ingested and of theorts, of Boer $x$ Saanen kid, in function of restriction level

\begin{tabular}{|c|c|c|c|c|c|}
\hline \multirow[t]{2}{*}{$\overline{\operatorname{Dieta}(\text { Diet })}$} & \multicolumn{3}{|c|}{ Restrição(Restriction) } & \multirow[t]{2}{*}{ Equações (Equations) } & \multirow[t]{2}{*}{$\mathrm{R}^{2}$} \\
\hline & $0 \%$ & $30 \%$ & $60 \%$ & & \\
\hline Oferecida $($ Offered $)(\mathrm{R} \$)$ & 23,39 & 14,14 & 8,33 & $Y=23,389-0,3654 X+0,0019 X^{2}$ & 0,94 \\
\hline Sobras $($ Orts $)(\mathrm{R} \$)$ & 3,05 & 0,17 & 0,03 & $Y=3,051-0,1415 X+0,0015 X^{2}$ & 0,97 \\
\hline Ingerida (Intake) $(\mathrm{R} \$)$ & 20,34 & 13,97 & 8,30 & $Y=20,338-0,2239 X+0,0004 X^{2}$ & 0,93 \\
\hline
\end{tabular}

$\mathrm{Y}=$ variável dependente $\mathrm{e} \mathrm{X}=$ variável independente (nível de restrição).

$\mathrm{Y}=$ depend variable and $\mathrm{X}=$ independent variable (level of restriction).

animais, com diferença $(\mathrm{p}<0,05)$ entre os tratamentos para quantidade (Tabela 3) e para custo da dieta (Tabela 4). Se forem confrontados os resultados do desempenho dos animais (Tabela 2) com os descritos nas Tabelas 3 e 4, verifica-se a necessidade de avaliação dos custos com alimentação por $\mathrm{kg}$ de carcaça produzida, pois a sobra de ração do tratamento $0 \%$ de restrição foi de $\mathrm{R} \$ 3,05$ por cabrito, que, dependendo do preço do animal e do rendimento de carcaça, poderá significar menor rentabilidade.

É importante salientar que, nas primeiras semanas de vida, o crescimento dos caprinos depende exclusivamente da ingestão de leite ou sucedâneos. Qualquer restrição neste período pode comprometer o desenvolvimento do animal, que será maior quanto mais precoce e intenso for a restrição do leite. Este fato foi observado por Manso et al. (1998), que, trabalhando com restrição alimentar durante o período de aleitamento em ovinos, observaram que a completa recuperação só ocorreu após os $20 \mathrm{~kg}$ de peso vivo (PV).

O custo da dieta ingerida apresentou efeito linear em relação aos tratamentos, ou seja, à medida que aumentou a restrição, diminuiu a diferença entre os custos da dieta oferecida com a ingerida (Tabela 4).
Como a dieta oferecida para os animais do tratamento $0 \%$ de restrição foi ajustada diariamente para permitir sobra de $15 \%$ e garantir a expressão máxima do potencial produtivo dos animais, o comportamento linear dos tratamentos foi confirmada, porém, o efeito quadrático foi mais representativo, pois os animais dos tratamentos com restrição tinham oferta em função do consumo dos animais com alimentação à vontade, e a restrição praticamente não permitiu sobras. Estes resultados sugerem que a restrição alimentar para animais de $15 \mathrm{~kg}$ e abatidos com PV médio de $20 \mathrm{~kg}$ pode significar melhor resposta econômica, uma vez que a redução nos custos com alimentação pode superar a receita obtida pelos quilogramas a mais de carcaça dos animais alimentados à vontade.

O fornecimento de alimento sólido de boa qualidade, durante o período de aleitamento dos ruminantes, visa estimular o desenvolvimento gastrintestinal, sobretudo dos pré-estômagos (Van Soest, 1992). Assim, quanto mais cedo ocorrer o consumo de alimentos sólidos, mais rápido será o desenvolvimento do rúmen, retículo e omaso, possibilitando a antecipação do desaleitamento e diminuindo os gastos 
com leite ou sucedâneo, o que pode repercutir positivamente na redução dos custos com alimentação por kg de carcaça produzida. Yáñez (2002), trabalhando com cabritos Saanen de 5 a $35 \mathrm{~kg}$ de PV, aleitados em condições semelhantes à deste trabalho, afirmou que os custos com alimentação foram maiores durante o aleitamento.

Na Tabela 5, é apresentada a análise econômica avaliada em diferentes níveis de restrição alimentar para cabritos F1 Boer x Saanen, considerando custo zero para a aquisição do cabrito ao nascimento. A restrição alimentar influenciou todas as variáveis analisadas, sendo linear decrescente para RBM e quadrática para $\mathrm{CuA}, \mathrm{MBM}, \mathrm{MBR}, \mathrm{RM}$ e IRR.

$O$ efeito quadrático sobre a MBM indica a possibilidade de restrição para os animais alimentados à vontade, que deverá ser praticada até o nível em que os custos do oferecido e consumido pelos animais com restrição se igualem. Neste trabalho, o nível estimado para permitir igualdade de custos da dieta oferecida e consumida pelos animais submetidos à restrição foi de $27,4 \%$, que, teoricamente, representa $\mathrm{R} \$ 14,72$.

A RM, que neste trabalho representa a rentabilidade sobre o investimento em alimentação, apresentou ponto de máximo quando o nível de restrição foi de $15,59 \%$, correspondendo a $48,07 \%$ de rentabilidade, permitindo IRR máximo de 106,20\%. Este resultado indica que o uso da restrição alimentar precisa ser melhor estudado, principalmente se forem considerados o concentrado utilizado, o preço praticado, a capacidade dos caprinos em aproveitar alimentos alternativos e demais variáveis que possam reduzir custos, sem interferir na qualidade e na comercialização da carne caprina. Afinal, o objetivo da restrição alimentar é atingir o ponto em que a redução nos custos da alimentação por kg de carcaça fria dos animais sob restrição represente maior rentabilidade que a gerada pelos animais alimentados à vontade.

A análise econômica considerando o custo de oportunidade de venda dos cabritos de $15 \mathrm{~kg}$ de PV, a preço de mercado $(\mathrm{R} \$ 3,50)$, para confinamento até atingir $25 \mathrm{~kg}$ é apresentada na Tabela 6. Embora a resposta econômica apresente o mesmo comportamento observado quando se considerou custo zero para aquisição do cabrito ao nascimento, a MBM e a RM diminuiu em relação aos resultados descritos na Tabela 5, indicando que a prática da restrição alimentar para cabrito de $15 \mathrm{~kg}$ comprado a preço de mercado e sua engorda até $25 \mathrm{~kg}$ caracteriza-se como atividade de risco.

No Brasil, a produção de carne de caprinos ocorre dentro do mesmo sistema, com cria, recria e engorda, isto é, os cabritos são mantidos no sistema de produção até o abate. Portanto, a criação dos machos e do excedente de fêmeas para produção de carne precisa ser melhor estudada, principalmente quanto à comercialização de animais recémdesaleitados, pesando em torno de $10 \mathrm{~kg}$ de PV, ou ao acabamento em pastejo ou confinado para obtenção de animais de 25 a $35 \mathrm{~kg}$ de PV.

$\mathrm{Na}$ Tabela 7, são apresentados os custos com alimentação por kg de PJ, de PCV, de PCQ e de PCF.

Tabela 5 - Médias, equações de regressão e coeficiente de determinação $\left(R^{2}\right)$ da análise econômica dos custos da alimentação de cabritos F1 Boer x Saanen, em função do nível de restrição, considerando custo zero para obtenção do cabrito

Table 5 - Averages, regression equations and coefficient of determination $\left(R^{2}\right)$ of the economic analysis of the costs of the feeding of Boer x Saanen kid, in function of restriction level, considering cost zero for obtaining of the kid

\begin{tabular}{|c|c|c|c|c|c|}
\hline \multirow[t]{2}{*}{ Item } & \multicolumn{3}{|c|}{ Restrição (Restriction) } & \multirow[t]{2}{*}{ Equações (Equations) } & \multirow[t]{2}{*}{$\mathrm{R}^{2}$} \\
\hline & $0 \%$ & $30 \%$ & $60 \%$ & & \\
\hline $\operatorname{RBM}(\mathrm{R} \$)^{1}$ & 82,87 & 69,67 & 52,70 & $Y=83,504-0,503 X$ & 0,95 \\
\hline $\mathrm{CuA}(\mathrm{R} \$)^{2}$ & 57,15 & 47,89 & 42,07 & $Y=57,139-0,365 X+0,0019 X^{2}$ & 0,94 \\
\hline $\operatorname{MBM}(\mathrm{R} \$)^{3}$ & 25,74 & 21,78 & 10,62 & $Y=25,736-0,012 X-0,0040 X^{2}$ & 0,81 \\
\hline $\operatorname{MBR}(\%)^{4}$ & 100,00 & 84,64 & 41,28 & $Y=100,000-0,045 X-0,0156 X^{2}$ & 0,85 \\
\hline $\mathrm{RM}(\%)^{5}$ & 45,26 & 45,67 & 25,24 & $Y=45,260+0,361 X-0,0116 X^{2}$ & 0,63 \\
\hline $\operatorname{IRR}(\%)^{6}$ & 100,00 & 100,91 & 55,77 & $Y=100,000+0,797 X-0,0256 X^{2}$ & 0,70 \\
\hline
\end{tabular}

$\mathrm{Y}=$ variável dependente e $\mathrm{X}=$ variável independente (nível de restrição); ${ }^{1}$ receita bruta média; ${ }^{2}$ custo com alimentação; ${ }^{3}$ margem bruta média; ${ }^{4}$ margem bruta relativa; ${ }^{5}$ rentabilidade média; ${ }^{6}$ índice relativo de rentabilidade.

$\mathrm{Y}=$ dependent variable and $\mathrm{X}=$ independent variable (level of restriction); ${ }^{1}$ average gross revenue; ${ }^{2}$ feeding cost; ${ }^{3}$ average gross margin; ${ }^{4}$ relative gross margin, ${ }^{5}$ average profitability, ${ }^{6}$ relative rentability index.

R. Bras. Zootec., v.34, n.1, p.188-196, 2005 
Tabela 6 - Médias, equações de regressão e coeficiente de determinação $\left(R^{2}\right)$ da análise econômica dos custos da alimentação de cabritos F1 Boer x Saanen, em função do nível de restrição, considerando o custo de oportunidade

Table 6 - Averages, regression equations and coefficient of determination $\left(R^{2}\right)$ of the economic analysis of the costs of feeding of Boer $x$ Saanen kid, in function of restriction level, considering the opportunity cost

\begin{tabular}{lccccc}
\hline Item & \multicolumn{3}{c}{ Restrição(Restriction) } & & Equações (Equations) \\
\cline { 2 - 4 } & $0 \%$ & $30 \%$ & $60 \%$ & & \\
\hline $\operatorname{RBM}(\mathrm{R} \$)^{1}$ & 82,87 & 69,67 & 52,70 & $\mathrm{Y}=83,504-0,503 \mathrm{X}$ & 0,95 \\
$\mathrm{CuA}(\mathrm{R} \$)^{2}$ & 74,94 & 64,88 & 59,14 & $\mathrm{Y}=74,94-0,407 \mathrm{X}+0,0024 \mathrm{X}^{2}$ & 0,97 \\
$\mathrm{MBM}(\mathrm{R} \$)^{3}$ & 7,94 & 4,82 & $-6,44$ & $\mathrm{Y}=7,94+0,032 \mathrm{X}-0,0045 \mathrm{X}^{2}$ & 0,82 \\
$\mathrm{MBR}(\%)^{4}$ & 100,00 & 60,72 & $-81,15$ & $\mathrm{Y}=100,000+0,4005 \mathrm{X}-0,0570 \mathrm{X}^{2}$ & 0,84 \\
$\mathrm{RM}(\%)^{5}$ & 10,61 & 7,49 & $-10,90$ & $\mathrm{Y}=10,61+0,151 \mathrm{X}-0,0085 \mathrm{X}^{2}$ & 0,81 \\
$\mathrm{IRR}(\%)^{6}$ & 100,00 & 70,63 & $-102,72$ & $\mathrm{Y}=100,000+1,421 \mathrm{X}-0,080 \mathrm{X}^{2}$ & 0,82 \\
\hline
\end{tabular}

$\mathrm{Y}=$ variável dependente e $\mathrm{X}=$ variável independente (nível de restrição); ${ }^{1}$ receita bruta média; ${ }^{2}$ custo com alimentação; ${ }^{3}$ margem bruta média; ${ }^{4}$ margem bruta relativa; ${ }^{5}$ rentabilidade média; ${ }^{6}$ índice relativo de rentabilidade.

$\mathrm{Y}=$ dependent variable and $\mathrm{X}=$ independent variable (level of restriction); ${ }^{1}$ average gross revenue; ${ }^{2}$ feeding cost; ${ }^{3}$ average gross margin; ${ }^{4}$ relative gross margin, ${ }^{5}$ average profitability, ${ }^{6}$ relative rentability index.

Para todos os parâmetros avaliados, o custo com alimentação por $\mathrm{kg}$ foi maior quando os animais foram submetidos a $60 \%$ de restrição, com igualdade de custos para os tratamentos com 0 e $30 \%$ de restrição. Esses resultados indicam que a resposta econômica à restrição deve ser melhor investigada, pois o objetivo é determinar o momento de maior ganho de massa muscular, para se obter maior retorno econômico por $\mathrm{kg}$ de carcaça e um produto final que atenda às exigências do consumidor.

Houve efeito quadrático com ponto ótimo de $15,24 \%$ de restrição e custo mínimo de 2,36 R $\$ / \mathrm{kg}$ de PJ. Com relação ao custo do kg de PCV, o nível ideal de restrição foi de 13,33\% e o custo mínimo da alimentação, de 2,84 R \$/kg de PCV. Essa variação entre os valores expresso em $\mathrm{kg}$ de PJ e kg de PCV reflete a variação do peso do conteúdo gastrintestinal.

Verificou-se que o fornecimento de dieta à vontade, apesar de ter proporcionado maior desempenho dos animais, não representou a melhor resposta econômica em termos de custo com alimentação por kg de carcaça produzido. O efeito quadrático foi caracterizado pela redução dos custos com alimentação por kg de PCQ até o nível de $16,68 \%$, que proporcionou $\mathrm{R} \$ 4,98$ de custo mínimo, a partir do qual a restrição alimentar não seria recomendável. Para carcaça fria, o custo com alimentação por $\mathrm{kg}$ diminuiu até a restrição de 16,13\% e proporcionou custo mínimo de $\mathrm{R} \$ 5,11$.

Dentro desse contexto, Yáñez (2002) observou que cabritos Saanen alimentados à vontade e abatidos com diferentes PV apresentaram custo de $\mathrm{R} \$ 4,44 / \mathrm{kg}$ de PCF para animais de $12,5 \mathrm{~kg}$ e de $\mathrm{R} \$ 3,59 / \mathrm{kg}$ para animais de $21 \mathrm{~kg}$ de PV. Os menores custos obtidos por Yáñez (2002), em parte, podem ser explicados pela diferença de preço dos ingredientes da dieta, principalmente do milho e da soja, que, em 2001, eram $40 \%$ menores que os preços utilizados neste trabalho. As diferenças seriam maiores se os cálculos fossem feitos em dólar, pois, em outubro de 2001, a relação dólar:real era, em média, de U\$1,00:R \$ 2,80 e, no mesmo mês de 2002, a relação girou em torno de $\mathrm{U} \$ 1,00: \mathrm{R} \$ 3,70$.

Os custos com alimentação por kg de PJ, PCV, PCQ e PCF, considerando a oportunidade de venda dos cabritos ao preço de mercado, são apresentados na Tabela 8. O elevado custo com alimentação confirma que a engorda de cabritos em sistemas exclusivo de confinamento, com ou sem restrição alimentar, necessita de mais estudos.

Por outro lado, a compra de cabritos $(15 \mathrm{~kg}$ de PV) a preço de mercado, para engorda em sistemas de confinamento, aumentou a relação custo:benefício, pois os melhores níveis de restrição e menores custos com alimentação por $\mathrm{kg}$ foram de $9,80 \%$ e $\mathrm{R} \$ 3,13$; $8,45 \%$ e $\mathrm{R} \$ 3,76 ; 12,53 \%$ e $\mathrm{R} \$ 6,59 ; 11,99 \%$ e $\mathrm{R} \$ 6,80$, respectivamente, para PJ, PCV, PCQ e PCF.

É importante ressaltar que os melhores resultados foram obtidos para a variável custos com alimentação por kg de PCQ e PCF, quando fossem considerados fatores de variação, como jejum de sólidos e líquidos e peso do conteúdo gastrintestinal, ou seja, expressam o custo com alimentação para cada $\mathrm{kg}$ de carcaça, que, na prática, representa o produto final que chega ao consumidor.

\section{R. Bras. Zootec., v.34, n.1, p.188-196, 2005}


Tabela 7 - Médias, equações de regressão e coeficiente de determinação $\left(R^{2}\right)$ do custo da alimentação por kg de peso em jejum (PJ), peso de corpo vazio (PCV), peso de carcaça quente (PCQ) e peso de carcaça fria (PCF) de cabritos F1 Boer x Saanen, em função do nível de restrição, considerando custo zero para obtenção do cabrito

Table 7 - Averages, regression equations and coefficient of determination $\left(R^{2}\right)$ of the cost of the feeding for $\mathrm{kg}$ fasting weight (FW), empty body weight (EBW), hot carcass weight (HCW) and cold carcass weight (CCW) of Boer $x$ Saanen kids, in function of restriction level, considering cost zero for obtaining of the kid

\begin{tabular}{|c|c|c|c|c|c|}
\hline \multirow[t]{2}{*}{ Custos (Cost) } & \multicolumn{3}{|c|}{ Restrição(Restriction) } & \multirow[t]{2}{*}{ Equações (Equations) } & \multirow[t]{2}{*}{$\mathrm{R}^{2}$} \\
\hline & $0 \%$ & $30 \%$ & $60 \%$ & & \\
\hline $\mathrm{kg} \mathrm{PJ}(\mathrm{R} \$)(k g F W)$ & 2,41 & 2,41 & 2,80 & $Y=2,414-0,0067 X+0,0002 X^{2}$ & 0,66 \\
\hline $\operatorname{kg} \mathrm{PCV}(\mathrm{R} \$)(k g E B W)$ & 2,89 & 2,92 & 3,48 & $Y=2,888-0,0078 X+0,0003 X^{2}$ & 0,79 \\
\hline $\operatorname{kg} \mathrm{PCQ}(\mathrm{R} \$)(\mathrm{kg} H C W)$ & 5,12 & 5,06 & 6,12 & $Y=5,127-0,0208 X+0,0006 X^{2}$ & 0,67 \\
\hline $\operatorname{kg} \mathrm{PCF}(\mathrm{R} \$)(k g C C W)$ & 5,29 & 5,24 & 6,40 & $Y=5,286-0,0215 X+0,0007 X^{2}$ & 0,69 \\
\hline
\end{tabular}

$\mathrm{Y}=$ variável dependente e $\mathrm{X}=$ variável independente (nível de restrição)

$\mathrm{Y}=$ dependent variable and $\mathrm{X}=$ independent variable (level of restriction)

Tabela 8 - Médias, equações de regressão e coeficiente de determinação $\left(R^{2}\right)$ do custo da alimentação por kg de peso em jejum (PJ), peso de corpo vazio (PCV), peso de carcaça quente (PCQ) e peso de carcaça fria (PCF) de cabritos F1 Boer x Saanen, em função do nível de restrição, considerando o custo de oportunidade

Table 8 - Averages, regression equations and coefficient of determination $\left(R^{2}\right)$ of the cost of the feeding for $\mathrm{kg}$ fasting weight (FW), empty body weight (EBW), hot carcass weight (HCW) and cold carcass weight (CCW) of Boer $x$ Saanen kids, in function of restriction level, considering the opportunity cost

\begin{tabular}{|c|c|c|c|c|c|}
\hline \multirow[t]{2}{*}{ Custos (Cost) } & \multicolumn{3}{|c|}{ Restrição (Restriction) } & \multirow[t]{2}{*}{ Equações (Equations) } & \multirow[t]{2}{*}{$\mathrm{R}^{2}$} \\
\hline & $0 \%$ & $30 \%$ & $60 \%$ & & \\
\hline $\operatorname{kg} \mathrm{PJ}(\mathrm{R} \$)(k g F W)$ & 3,17 & 3,26 & 3,94 & $Y=3,165-0,0063 X+0,0003 X^{2}$ & 0,83 \\
\hline $\operatorname{kg} \mathrm{PCV}(\mathrm{R} \$)(\mathrm{kg} E B W)$ & 3,79 & 3,96 & 4,90 & $Y=3,788-0,0073 X+0,0004 X^{2}$ & 0,88 \\
\hline $\operatorname{kg} \mathrm{PCQ}(\mathrm{R} \$)(\mathrm{kg} H C W)$ & 6,73 & 5,06 & 8,60 & $Y=6,729-0,0224 X+0,0009 X^{2}$ & 0,76 \\
\hline $\operatorname{kg} \mathrm{PCF}(\mathrm{R} \$)(\mathrm{kg} C C W)$ & 6,94 & 5,24 & 8,99 & $Y=6,938-0,0233 X+0,001 X^{2}$ & 0,77 \\
\hline
\end{tabular}

$\mathrm{Y}=$ variável dependente $\mathrm{e} \mathrm{X}=$ variável independente (nível de restrição).

$\mathrm{Y}=$ dependent variable and $\mathrm{X}=$ independent variable (level of restriction).

São raros os trabalhos com restrição alimentar quantitativa em caprinos, e os poucos existentes não avaliam o efeito da restrição sobre o rendimento econômico, restringindo-se a avaliar as respostas quantitativas e qualitativas na carcaça, qualidade da carne e, às vezes, o crescimento tecidual. Diante da escassez de literatura e com base nesses resultados, tornam-se necessários alguns questionamentos sobre o uso ou não da restrição alimentar, principalmente no que se refere aos níveis a serem praticados, à periodicidade (contínua ou temporária), à exploração do crescimento compensatório (presente ou ausente), entre outros aspectos que possam refletir sobre a rentabilidade do sistema de produção.

A partir dos resultados obtidos com animais da raça Saanen por Yáñez (2002) e os observados com animais F1 Boer x Saanen neste trabalho, constatase que pesquisadores e criadores devem refletir mais sobre o uso de cruzamentos, seus objetivos e as metas a serem atingidas.
É imprescindível reconhecer que os aspectos relacionados à qualidade do produto final dependem do consumidor, que, muitas vezes, reivindica produtos com características que se contrastam, como carne magra e suculenta. Ao produtor resta entender as exigências dos consumidores e buscar alternativas para atendê-las, sem comprometer a sustentabilidade do sistema de produção.

\section{Conclusões}

A restrição alimentar praticada em níveis moderados mantém a eficiência alimentar e reduz as perdas com alimentação.

A utilização de cabritos leiteiro para o abate entre 20 e $25 \mathrm{~kg}$ de PV, com restrição alimentar a partir dos $15 \mathrm{~kg}$, aumenta a rentabilidade sobre o investimento em alimentação até o nível de $15,59 \%$ e diminui, gradativamente, os custos com alimentação por $\mathrm{kg}$ de carcaça fria até o nível de $16,13 \%$ de restrição, caracterizando-se como al-

R. Bras. Zootec., v.34, n.1, p.188-196, 2005 
ternativa ao sacrifício desses animais ao nascimento e proporcionando maior rendimento econômico ao sistema de produção. A compra de cabritos ao preço de mercado para terminação até $25 \mathrm{~kg}$ de $\mathrm{PV}$, por sua vez, caracteriza-se como atividade de risco.

\section{Literatura Citada}

AGRICULTURAL AND FOOD RESEARCH COUNCIL AFRC. The nutrition of goat. Report 10. Nutr. Abstr. Revision (Series B), Aberdeen, 1998. v.67, n.11, 118p.

ARRIGONI, M.B.; VIEIRA, P.F.; SILVEIRA, A.C. et al. Estudo dos efeitos da restrição alimentar nas características das fibras musculares de bovinos jovens confinados. Pesquisa Agropecuária Brasileira, v.33, n.7, p.1121-1127, 1998.

CENTRO DE ESTUDOS AVANÇADOS EM ECONOMIA APLICADA ESALQ - USP. Indicadores de preços. Cepea, Piracicaba, out. 2002. Disponível em: www.cepea.esalq.usp.br. Acesso em: 05 out. 2002.

CHURCH, D.C. El rumiant fisiologia digestiva y nutrición. Zaragoza: 1993. 641p.

GENANDOY, H.; SAHLU, T.; DAVIS, J. et al. Effects of different feeding methods on growth and harvest traits of young Alpine kids. Small Ruminant Research, v.44, p.81-87, 2002.

LANA, G.R.Q.; ROSTAGNO, H.S.; DONZETE, J.L. et al. Efeito de programas de restrição alimentar sobre o desempenho produtivo e econômico e a deposição de gordura na carcaça de frango de corte. Revista Brasileira de Zootecnia, v.28, n.6, p.1302-1309, 1999.

MANSO, T.; MANTECÓN, A. R.; CASTRO, T. et al. Effect of intake level during milk-feeding period and protein content in the pos-weaning diet on performance and body composition in growing lambs. Animal Science, v.67, p.513-521, 1998.

MEJÍA, J.M.J.; CASTRO, A.C.G.; SILVA, J.F.C. et al. Análise da eficiência técnica e econômica do uso do farelo de gérmen de milho na alimentação de bezerros. I. Período ótimo de aleitamento. In: REUNIÃO ANUAL DA SOCIEDADE BRASILEIRA DE ZOOTECNIA, 33., 1996, Fortaleza. Anais... Fortaleza: Universidade Federal do Ceará, 1996a. v.1, p.597-599.

MEJÍA, J.M.J.; CASTRO, A.C.G.; SILVA, J.F.C. et al. Análise da eficiência técnica e econômica do uso do farelo de gérmen de milho na alimentação de bezerros. II. Custo da alimentação na fase de pós-aleitamento. In: REUNIÃO ANUAL DA SOCIEDADE BRASILEIRA DE ZOOTECNIA, 33., 1996, Fortaleza. Anais... Fortaleza: Universidade Federal do Ceará, 1996b. v.1, p.600-602.
MORON-FUENMAYOR, O.E.; CLAVERO, T. The effect of feeding system on carcass characteristics, non-carcass components and retail cut percentages of lambs. Small Ruminant Research, v.34, p.57-64, 1999.

MTEMGA, L.A.; KITALY, A.J. Growth performance and carcass characteristics of Tanzanian goats fed Chloris gayana hay with different levels of protein supplement. Small Ruminant Research, v.3, p.1-8, 1990.

OMAN, J.S., WALDRON, D.F.; GRIFFIN, D.B. et al. Effect of breed-type and feeding regime on goat carcass traits. Journal Animal Science, v.77, p.3215-3218, 1999.

PEREIRA FILHO, J.M.; TRINDADE, I.A.M.C.; RESENDE, K.T. et al. Biometria do trato gastrintestinal em cabritos $1 / 2$ sangue (Boer x Saanen. In: REUNIÓN DA ASSOCIACIÓN LATINOAMÉRICANA DE PRODUCCIÓN ANIMAL, 17., 2001. Habana - Cuba Memorias... Habana - Cuba 2001, (CD Rom). Nutrição de ruminantes.

RIBEIRO, S.D.A. Caprinocultura: criação racional de caprinos. São Paulo: Nobel, 1997. 311p.

RESENDE, K.T. Distribuindo os partos ao longo do ano: o sistema da Unesp - Jaboticabal. Capritec, Espirito Santo do Pinhal, out. 2002. Seção Textos Técnicos e Artigos. Disponível em: www.capritec.com.br. Acesso em: 08 out. 2002.

SAHLU, T.; HART, S.P.; GOETSCH, A.L. Effects of level of feed intake on body weigth, body components, and mohair growth in Angora goats during realimentation. Small Ruminant Research, v.32, p.251-259, 1999.

STATISTICAL ANALYSIS SYSTEMS INSTITUTE - SAS. User's guide. Cary: 1999.

Van SOEST, P.J. Nutritional ecology of the ruminant. New York: Cornell University Press, 1992. 476p.

YÁÑEZ, E.A. Desenvolvimento relativo dos tecidos e características da carcaça de cabritos Saanen, com diferentes pesos e níveis nutricionais. Jaboticabal: Universidade Estadual Paulista, 2002. 85p. Tese (Doutorado em Zootecnia). Universidade Estadual Paulista, 2002.

Recebido em: 11/08/03 Aceito em: 23/11/04 